\title{
Damage of lipopolysaccharides in outer cell membrane and production of ROS-mediated stress within bacteria makes nano zinc oxide a bactericidal agent
}

\author{
Prasun Patra $\cdot$ Shuvrodeb Roy $\cdot$ Sampad Sarkar • \\ Shouvik Mitra · Saheli Pradhan • Nitai Debnath • \\ Arunava Goswami
}

Received: 15 October 2014/Accepted: 8 December 2014/Published online: 23 December 2014

(C) The Author(s) 2014. This article is published with open access at Springerlink.com

\begin{abstract}
Zinc oxide nanoparticle (ZNP) has been synthesized by microwave-assisted technique with the aid of a buffer solution. ZNP inhibited the growth of bacterial system Escherichia coli, even its multidrug-resistant counterpart as well. Systematic evaluation reveals that bioavailable crystalline ZNP damages the lipopolysaccharide layer from outer membrane (OM) of E. coli, subsequently damages the $\mathrm{OM}$ followed by inner membrane, enters within the cell and generates extensive reactive oxygen species-mediated damage. A series of biochemical, biophysical and molecular techniques have been used to reach the conclusion. We believe this work is expected to enlighten the detailed mode of action study in bacterial system.
\end{abstract}

Keywords Zinc oxide nanoparticle (ZNP) - Escherichia coli $\cdot$ Lipopolysaccharide (LPS) · Inner membrane (IM) · Outer membrane $(\mathrm{OM})$

P. Patra $(\square)$

Centre for Research in Nano Science and Nano Technology, Technology Campus, University of Calcutta, JD 2, Sec III, Salt lake, Kolkata 700098, India

e-mail: bioprasun@gmail.com

S. Roy $\cdot$ S. Sarkar $\cdot$ S. Mitra $\cdot$ S. Pradhan $\cdot$ A. Goswami Biological Sciences Division, Indian Statistical Institute, 203, B. T. Road, Kolkata 700108, India

N. Debnath

Department of Biotechnology, Amity University, Gurgaon, India

\section{Introduction}

The ongoing worldwide nanotechnology revolution is predicted to impact several areas of biomedical research and engineering applications. Progress in utilizing inorganic nanoparticles (NP) for biomedical applications has advanced rapidly as a result of the extensive amount of work done in the synthesis and fabrication of smart NP (Liong et al. 2008). Among inorganic materials, metal oxide NPs are of special interest; especially zinc oxide $(\mathrm{ZnO})$ which has photocatalytic property, photo-oxidizing ability against chemical and biological species (Szabo et al. 2003). $\mathrm{ZnO}$ nanostructures are available in wide varieties, among them flower-like, snowflake-like, prism-like, prickly sphere-like and rod-like shapes have already been investigated (Jung et al. 2008). ZNP have been broadly used as an inorganic antibacterial agent. The ability to withstand harsh processing, its high durability in comparison with organic materials made it suitable for development of a stable antibacterial agent (Anagnostakos et al. 2008). A handful of literatures are available on the antibacterial activity of ZNP (Sawai 2003; Jones et al. 2008; Mitra et al. 2012; Augustine et al. 2014a, b; RodríguezTobías et al. 2014). A size-dependant bactericidal activity of ZNP has also been noted (Mitra et al. 2012). The resistance of Gram-negative bacteria to ZNP than the Gram-positive bacteria was also reported (Zarrindokht and Pegah 2011). There have been a lot of speculations about the mode of action of ZNP as an antibacterial agent. Considerable antibacterial activity of ZNP is attributed to the generation of reactive oxygen species (ROS) on the surface of these oxides (Applerot et al. 2009; Augustine et al. 2014a, b; Maschhoff et al. 2014). Although there is no ambiguity over the formation of ROS and it can be considered that ROS does the fatal damage to the bacterial 
system, how the as formed ROS reaches the bacterial cell to execute the lethal response is yet to resolve. In this context, we describe a detailed study using biochemical, biophysical and molecular technique to construct a mechanistic pathway in a bacterial system which suffers from ROS burden generated by ZNP in post-treated condition.

The bacterial outer membrane (OM) is mainly found in Gram-negative bacteria. OM functions as an efficient permeability barrier that is able to exclude macromolecules (such as bacteriocins or enzymes) and hydrophobic substances (i.e., hydrophobic antibiotics). The permeability barrier property of the OM is largely due to the presence of a specific lipopolysaccharide (LPS) layer on the membrane surface. LPS molecules consist of a lipid part, termed lipid $\mathrm{A}$, and a hydrophilic heteropolysaccharide chain protruding outward and providing the cell with a hydrophilic surface (Raetz et al. 2002). Certain external agents either release LPS and other components from the OM or intercalate in the membrane, causing abolition of the integrity of the OM. In both cases there is a concomitant loss of the permeability barrier function.

In this study, we first time report that the bioavailable crystalline ZNP damages the LPS layer from OM of Escherichia coli, subsequently damages the OM followed by inner membrane, enters within the cell and generates extensive ROS-mediated damage. Although the mode of ROS generation is same, here we have highlighted the mechanistic pathway of pre-ROS generation leading to the bioavailability of ZNP within cellular system of bacteria to sustain the fatal damage. This work is expected to enlighten the detailed mode of action of ZNP within a bacterial system.

\section{Materials and methods}

\section{Synthesis of ZNP}

ZNP was synthesized using our previously reported method using tris(hydroxymethyl)aminomethane (TRIS) buffer as the growth directing agent (Patra et al. 2012). Briefly, to a $25 \mathrm{~mL}$ of $0.05 \mathrm{M}$ zinc acetate solution $20 \mathrm{~mL}$ of $20 \%$ TRIS solution was added with vigorous stirring. The mixture was then subjected to a domestic microwave heating for $3 \mathrm{~min}$ at 300 watt. The resultant ZNP was centrifuged at 10,000 rpm and washed several times with deionized water to remove excess of TRIS buffer, finally the product was dried at $80{ }^{\circ} \mathrm{C}$ for overnight.

\section{MIC determination}

Normal E. coli (MTCC 443) strain was obtained from Microbial Type Culture Collection (MTCC), Chandigarh.
The antibacterial activity of ZNP was evaluated by measuring the minimum inhibitory concentration (MIC) by both agar dilution method (ADM) and broth microdilution method (BMD) following standard procedure (Wayne 2008).

Bactericidal assay against clinically isolated multidrugresistant bacteria

Clinically isolated multidrug-resistant strains of E. coli were isolated and cultured following standard method (Dutta et al. 2010). Then concentrations of all strains were adjusted to $\sim 10^{4} \mathrm{CFU} / \mathrm{mL}$ with sterile nutrient broth. ZNP was added to final concentrations of 10, 20, 40, 80, 160, 320,500 and $1,000 \mu \mathrm{g} / \mathrm{mL}$, respectively, in Luria broth (LB) and mixed homogenously by sonication. $50 \mu \mathrm{L}$ of each bacterial suspension was added to each concentration and incubated at $37{ }^{\circ} \mathrm{C}$ for $24 \mathrm{~h}$. Bacterial growth was measured spectrophotometrically at $600 \mathrm{~nm}$.

Release of lipopolysaccharides (LPS) study by SDSPAGE

The release of LPS in response to external agents was determined by sodium dodecyl sulfate-polyacrylamide gel electrophoresis (SDS-PAGE) of cell free supernatants of E. coli (MTCC 443) with ZNP treatment compared with control (Helander et al. 1998). LPS preparations were analyzed by $12 \%$ SDS-PAGE study.

\section{Integrity of cell membranes}

If the bacterial membrane was compromised, release of inner cellular constituents could be monitored. By measuring the absorbance at $260 \mathrm{~nm}$, one could estimate the amount of DNA and RNA released from the inner cellular constituents. The bacterial suspension was separated into several flasks. Different concentrations of ZNP were added to each flask except the control. $1.5 \mathrm{~mL}$ of samples was removed from the flasks after every $20 \mathrm{~min}$. The samples were then immediately filtered with $0.2-\mathrm{mm}$ syringe filters to remove the bacteria, supernatants were then diluted appropriately and optical density at $260 \mathrm{~nm}$ was recorded (Chen and Cooper 2002).

Outer membrane permeabilization assay

Outer Membrane permeation activity of ZNP was determined by the NPN (1- $N$-phenylnaphthylamine) assay (Ibrahim et al. 2000). Escherichia coli (MTCC 443) cells grown in LB medium (to an optical density of $\mathrm{A}_{600}$ of 0.4 ) were collected, washed twice and resuspended in $5 \mathrm{mM}$ sodium HEPES buffer, pH 7.2, containing $1 \mathrm{mM} \mathrm{KCN}$. To $1 \mathrm{~mL}$ volume of bacteria in a quartz cuvette, NPN was added (final 
concentration: $10 \mu \mathrm{M}$ ), background fluorescence was recorded using a PerkinElmer LS 55 spectrophotometer. Excitation and emission wavelengths were adjusted at 350 and $429 \mathrm{~nm}$, respectively. Aliquots of peptide (various concentrations) were added, increase in fluorescence due to partitioning of NPN into the OM was recorded as a function of time until no further increase in intensity was noted. Control tests were performed to verify that the enhanced fluorescence was due to NPN uptake by bacteria.

Inner membrane permeabilization assay

Inner Membrane permeation of E. coli (MTCC 443) was determined by measuring the release of L-galactosidase activity into the culture medium using ONPG (o-nitrophenyl-L-D-galactoside) as a substrate (Kumar and Raji 2011). Bacteria grown to logarithmic phase in LB medium containing $2 \%$ lactose were collected, washed and resuspended (to give $10^{9} \mathrm{CFU} / \mathrm{mL}$ ) in $10 \mathrm{mM}$ sodium phosphate buffer, $\mathrm{pH} 7.5$, containing $100 \mathrm{mM} \mathrm{NaCl}$. Bacterial suspension $(200 \mu \mathrm{L})$ was pipetted into the wells of a standard microtiter plate followed by addition of $10 \mu \mathrm{L} \mathrm{ZNP}$ at different concentrations to each well. Plates were incubated with gentle rocking at $37^{\circ} \mathrm{C}$ and the production of $o$ nitrophenol over time was monitored with a spectrophotometer at $420 \mathrm{~nm}$. To distinguish between release of the cytoplasmic enzyme and ZNP uptake into cells, the bacteria were removed by centrifugation after 60 -min incubation with the peptide. Then the release of L-galactosidase in the medium supernatant was measured. Release was quantified as production of $o$-nitrophenol (ONP) per minute per $\mathrm{mL}$ and calculated using the following formula: $\left[\mathrm{A}_{415}\right.$ $\times 1000 /$ sample volume $(\mu \mathrm{L})] /$ reaction time $(\min ) \times 4.86$, where $\mathrm{A}_{415}$ and 4.86 were the absorbance at 415 after a certain time of enzyme reaction and the extinction coefficient $\left(\mathrm{mM}^{-1} \mathrm{~cm}^{-1}\right)$ of ONP, respectively.

\section{Cell morphology study by FESEM and TEM}

For electron microscopic studies (Field Emission Scanning Electron Microscope and Transmission Electron Microscope), bacterial samples were cultured using the same procedure as already described in MIC determination. Then these bacterial samples were washed with cold water and suspended in cold $0.5 \mathrm{M}$ phosphate buffer ( $\mathrm{pH}$ 7.0) followed by fixing in $4 \%$ glutaraldehyde at $4{ }^{\circ} \mathrm{C}$ for $1 \mathrm{~h}$. Then samples were stained with $1 \%$ osmium tetroxide solution and dehydrated by graded ethanol (Hartmann et al. 2010).

SDS-PAGE of whole cell proteins

Escherichia coli cells were grown in LB growth media using standard procedure described above. After $24 \mathrm{~h}$ of inoculation $1 \mathrm{~mL}$ of control and treated bacterial samples were spin down at 3,000 rpm and washed twice to remove excess LB media from pellets with PBS $(1 \times)$ buffer. 250 $\mu \mathrm{L}$ of $1 \times$ SDS-PAGE loading buffer was added to each cell pellets and vortex until cells were resuspended. Then cells were boiled $5 \mathrm{~min}$ in $\mathrm{H}_{2} \mathrm{O}$ bath, the samples were centrifuged at $300 \mathrm{rpm}$ and supernatants were used for $12 \%$ SDS-PAGE study (Lasserre et al. 2006).

Cell permeabilization study by confocal microscope

For confocal microscopic study ZNP was converted into its fluorescent counterpart by conjugation of rhodamine-Bisothiocyanate (RITC) using our previous method. Escherichia coli cultured in LB was incubated with 200 and $100 \mu \mathrm{g} / \mathrm{mL}$ of RITC-conjugated ZNP for $24 \mathrm{~h}$, respectively, and bacterial samples were isolated and prepared using standard protocol as mentioned above. Finally, the samples were fixed with glue (Tissue-Tek, Sakura) and observed under confocal microscope (Zeiss).

\section{Synthesis of RITC-conjugated ZNP}

RITC-conjugated ZNP was synthesized in two steps, first one involved the conversion of ZNP into amine-functionalized ZNP while the second step involved conjugation of RITC to amine-functionalized ZNP.

\section{Synthesis of amine-functionalized ZNP}

Amine functionalization of ZNP was carried out using 3-aminopropyltriethoxysilane (APTES) via co-condensation reaction using our previously reported method (Patra et al. 2012). In brief, about $0.5 \mathrm{~g}$ of ZNP was dispersed in about $50 \mathrm{~mL}$ of DMSO in a sonication bath for about $1 \mathrm{~h}$. To it, $400 \mu \mathrm{L}$ of APTES was added and the solution was refluxed at $120{ }^{\circ} \mathrm{C}$ for about $3 \mathrm{~h}$. After completion of the reaction the resulting amine-functionalized ZNP was centrifuged at 12,000 rpm for about $15 \mathrm{~min}$ and washed several times with ethanol to remove the unreacted APTES. Finally, the product was dried at $60{ }^{\circ} \mathrm{C}$ for overnight to produce amine-functionalized ZNP.

\section{Conjugation of RITC to amine-functionalized ZNP}

Amine-functionalized $\mathrm{ZNP}$ of appropriate concentration was dispersed in $0.1 \mathrm{M} \mathrm{NaHCO}_{3}$ solution, to it $1 \mathrm{mg}$ of RITC dissolved in $2 \mathrm{~mL}$ of aqueous DMSO (1:1, v/v) was added instantly and the reaction mixture was stirred at room temperature for $24 \mathrm{~h}$ in a dark condition. RITCconjugated ZNP (ZNP-RITC) was separated by centrifugation at $10,000 \mathrm{rpm}$ at $4{ }^{\circ} \mathrm{C}$. ZNP-RITC was washed and 
redispersed in water repeatedly to remove excess of RITC (Patra et al. 2012).

Energy-dispersive X-ray (EDX) spectroscopic analysis of bacterial samples

For EDX analysis, bacterial samples were cultured as described for MIC determination as mentioned above. These bacterial samples were washed with cold water and suspended in cold $0.5 \mathrm{M}$ phosphate buffer ( $\mathrm{pH}$ 7.0) followed by fixing in $4 \%$ glutaraldehyde at $4{ }^{\circ} \mathrm{C}$ for $1 \mathrm{~h}$. Then samples were stained with $1 \%$ osmium tetroxide solution and dehydrated by graded ethanol. This sample was directly used for SEM and EDX analysis, gold and carbon coating was avoided (Hartmann et al. 2010).

\section{Carbonyl content assay by DNPH binding assay}

Protein carbonyl content, a marker of oxidative stress, was measured spectrophotometrically following slightly modified 2,4-dinitrophenylhydrazine (DNPH) binding assay (Krumova et al. 2009). All bacterial samples were cultured in LB media; then incubated at $37^{\circ} \mathrm{C}$ with vigorous shaking for $24 \mathrm{~h}$ for proper growth of bacterial cells. After $24 \mathrm{~h}$ of incubation bacterial cells were isolated from culture and washed with $50 \mathrm{mM}$ phosphate buffer ( $\mathrm{pH} 7.0$ ). The samples were then freeze dried with liquid nitrogen and ground with an ice-cold mortar pestle using $8 \mathrm{~mL}$ of $50 \mathrm{mM}$ phosphate buffer ( $\mathrm{pH}$ 7.0). The homogenates were centrifuged at $5,000 \mathrm{rpm}$ for $20 \mathrm{~min}$ at $4{ }^{\circ} \mathrm{C}$. The supernatants were incubated with DNPH for $1 \mathrm{~h}$ at $37^{\circ} \mathrm{C}$; proteins were precipitated in $10 \%$ cold trichloroacetic acid (TCA) and washed with ethanol: ethyl acetate (1:1) to remove excess DNPH. Finally samples were dissolved in $6 \mathrm{M}$ guanidine chloride ( $\mathrm{pH} 2)$. The optical density was measured at $380 \mathrm{~nm}$ and the carbonyl content was calculated using a molar extinction coefficient of $21 / \mathrm{mM} \mathrm{cm}$, resulting in final measurement of nanomoles of DNPH incorporated (protein carbonyls) per $\mathrm{mg}$ of protein (Krumova et al. 2009).

\section{Results}

Physicochemical characterizations of ZNP

Morphology of ZNP was confirmed by FESEM (Fig. 1a) and TEM (Fig. 1b) analyses. FESEM image of ZNP justified the spherical morphology while absolute size was determined by TEM. TEM image suggested more or less spherical particles of sizes around $20 \mathrm{~nm}$. Crystalline structure was further confirmed by selected area diffraction (SAED) pattern as well (Fig. 1b inset).

MIC determination, bactericidal assay against multidrug-resistant bacteria

MIC value of ZNP was found to be $\sim 200 \mu \mathrm{g} / \mathrm{mL}$ in case of E. coli (MTCC 443). MIC value obtained by ADM was detected to be as $200 \mu \mathrm{g} / \mathrm{mL}$ while the same by BDM was found to be $180 \mu \mathrm{g} / \mathrm{mL}$. The closeness of the two results justified that no significant anomalies were present during MIC determination. Therefore, buffer mediated synthesized ZNP was effective against Gram-negative bacteria. To pursue the effect of ZNP on multidrug-resistant bacteria, multidrug-resistant $E$. coli were chosen as the model organism to verify the antibacterial effect of ZNP on bacterial system as mentioned for MTCC 443. The antibiogram of these multidrug-resistant bacteria is shown in Table 1.

ZNP showed a significant growth inhibition compared with the control against drug-resistant bacterial strains of E. coli. The dynamics of bacterial growth were monitored after $24 \mathrm{~h}$ of inoculation of bacteria by measuring the OD (at $600 \mathrm{~nm}$ ) of the control, and bacterial solutions supplemented with different concentrations of ZNP shown in
Fig. 1 a FESEM and b TEM image of ZNP, inset signified its SAED pattern
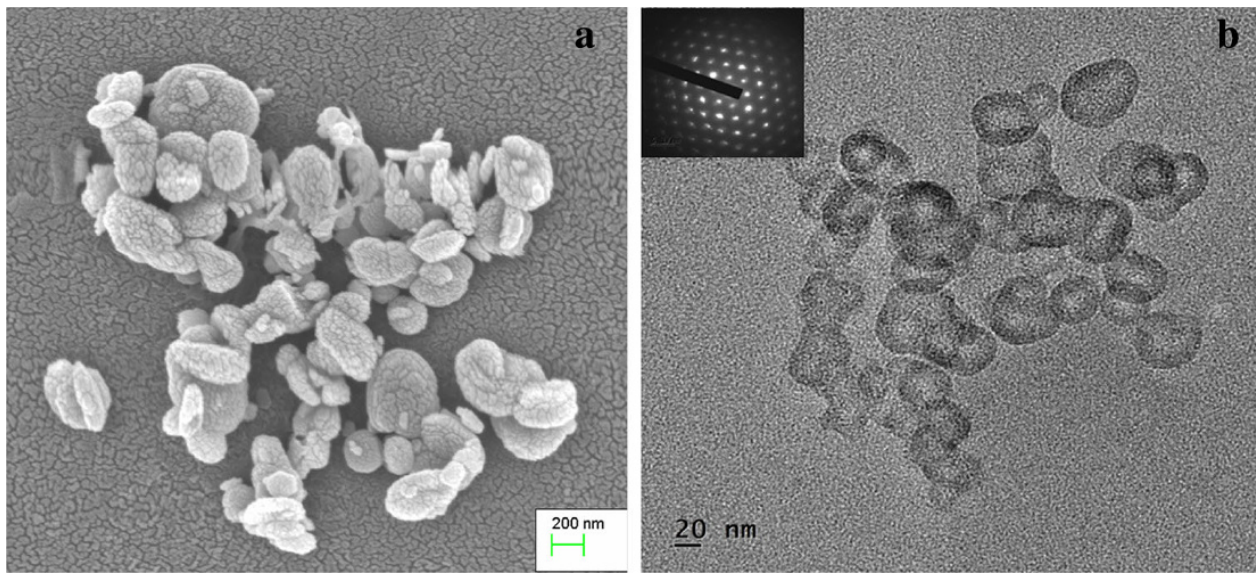
Table 1 Antibiogram of clinically isolated two strains of E. coli (ZZ 1754 and MS 4678)

\begin{tabular}{llll}
\hline S1 no. & Drugs applied & E. coli $($ ZZ 1754) & E. coli (MS 4658) \\
\hline 1. & Levofloxacin & Moderately sensitive & Highly sensitive \\
2. & Meropenem & Moderately sensitive & Highly sensitive \\
3. & Sparfloxacin & Moderately sensitive & Highly sensitive \\
4. & Imipenem & Intermediate & Highly sensitive \\
5. & Amikacin & Intermediate & Moderately sensitive \\
6. & Amoxycillin & Intermediate & Moderately sensitive \\
7. & Cefotaxime & Intermediate & Moderately sensitive \\
8. & Ceftriaxone & Intermediate & Moderately sensitive \\
9. & Cefuroxime & Resistant & Moderately sensitive \\
10. & Cephalexin & Resistant & Moderately sensitive \\
11. & Ciprofloxacin & Resistant & Moderately sensitive \\
12. & Co-trimoxazole & Resistant & Moderately sensitive \\
13. & Doxycycline & Resistant & Moderately sensitive \\
14. & Gentamicin & Resistant & Moderately sensitive \\
15. & Netilmicin & Resistant & Intermediate \\
16. & Nitrofurantoin & Resistant & Resistant \\
17. & Ofloxacin & Resistant & Resistant \\
18. & Piperacillin & Resistant & Resistant \\
19. & Tobramycin & Resistant & Resistant \\
\hline & & &
\end{tabular}

Fig. 2. It was clear that at all these concentrations, the nanoparticles caused a growth delay of the bacterial cells; slope of the bacterial growth curve was continuously decreased with increasing ZNP concentration. ZNP of highest concentration $(500 \mu \mathrm{g} / \mathrm{mL})$ showed no growth after $24 \mathrm{~h}$ of inoculums in multidrug-resistant $E$. coli. Therefore, MIC was determined to be $500 \mu \mathrm{g} / \mathrm{mL}$ for multidrugresistant E. coli which was consistent with MTCC 443; drug resistance justified high concentration use of ZNP to inhibit bacterial growth inhibition.

Integrity of bacterial cell membranes

The cytoplasmic cell membrane is a structural component, which may become damaged and functionally invalid when bacterial suspensions are exposed to antibacterial agents. If bacterial membrane became compromised, small ions such as $\mathrm{K}^{+}$and $\mathrm{PO}_{4}{ }^{3-}$ tend to leach out first, followed by large molecules such as DNA, RNA and other materials. The release of intracellular components with strong UV absorption at $260 \mathrm{~nm}$ is an indication of membrane damage (Ibrahim et al. 2000). When E. coli suspensions were treated with ZNP and then subjected to spectrophotometric determination; at first the $\mathrm{A}_{260}$ increased rapidly then at a decreasing rate up to $180 \mathrm{~min}$ (Fig. 3a). This signified the damage of cell membrane of $E$. coli by ZNP which allowed the leaching of DNA and RNA content. The damage of cell membranes by ZNP followed a concentration-dependent

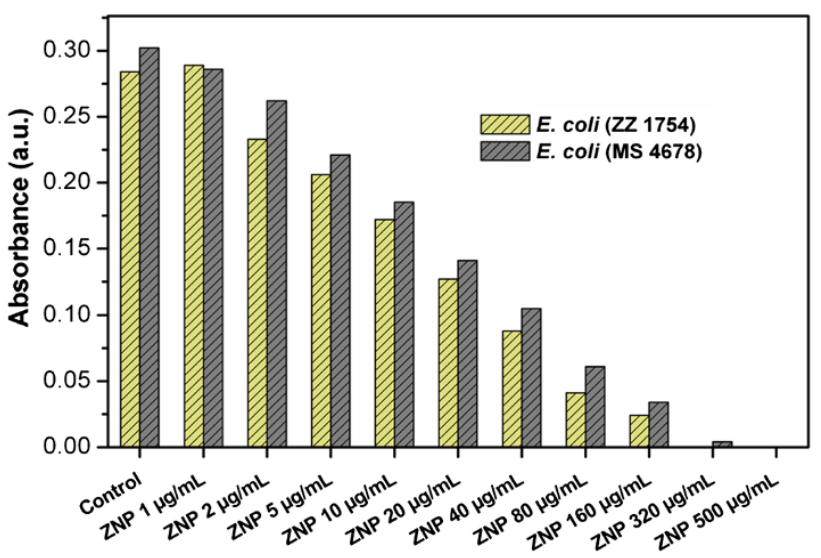

Fig. 2 Antibacterial effects of ZNP against clinically isolated multidrug-resistant E. coli strains (ZZ 1754 and MS 4678)

pathway and was consistent with the findings for bactericidal activity.

Release of LPS study by SDS-PAGE

Release of LPS in supernatants was determined by SDSPAGE. The results revealed that ZNP-treated cells released higher amount of LPS into supernatant compared to the control ones shown in ladder pattern. Results clearly showed (Fig. 3b) that the banding pattern of LPS was different between control and treated samples. This was probably due to the damage sustained by crystalline ZNP interacting with the surface of LPS. As already mentioned that ZNP was hydrophilic in nature and therefore interacted with the hydrophilic counterpart of LPS resulting in deformation; hence banding pattern was changed significantly in the treated samples.

\section{Outer membrane permeabilization assay}

Gram-negative bacteria such as E. coli have two cell envelope membranes. The ability of ZNP to interact with both outer and inner membranes was examined. NPN, which is a hydrophobic probe, is normally excluded by an intact outer membrane of Gram-negative bacteria. Increased fluorescence uptake of NPN occurs in bacterial suspensions containing cells whose outer membranes are damaged and functionally invalid, since the quantum yield of NPN is greatly increased (Ibrahim et al. 2000). The addition of ZNP to $E$. coli suspensions in the presence of NPN caused a time-dependent increase in fluorescence intensity (Fig. 3c). The relative fluorescence increased to a maximum within $10 \mathrm{~min}$. Fluorescence property in the treated samples exhibited dose dependency, i.e., increased with the concentration of ZNP. These results suggested that ZNP rapidly increase the permeability of the OM of cells. 

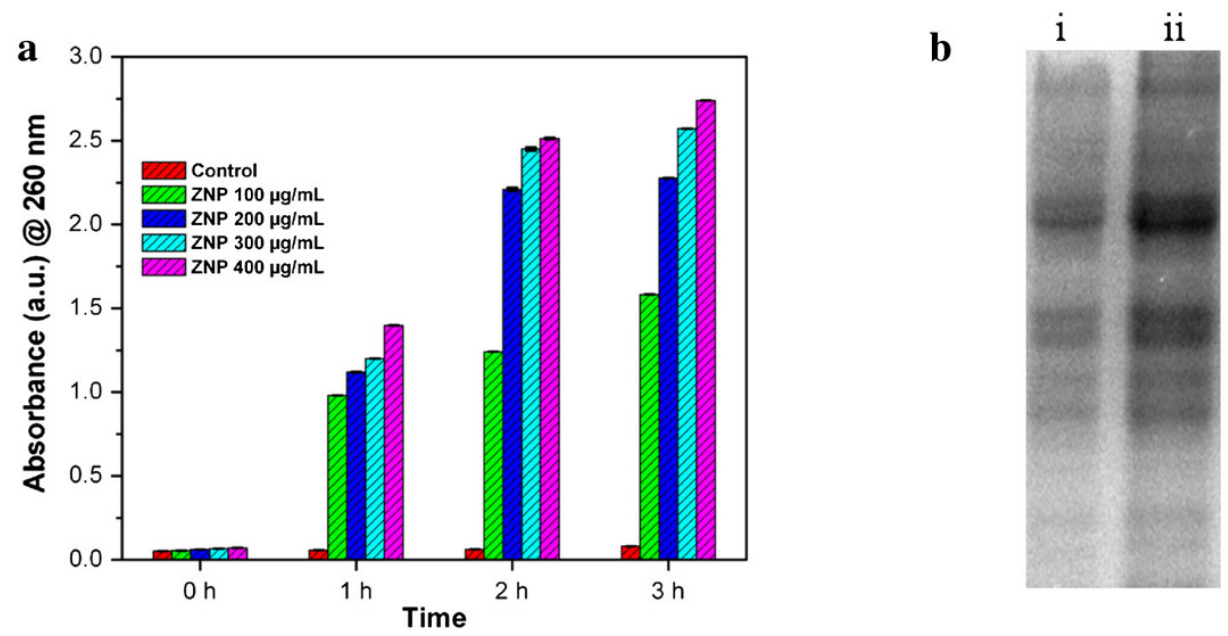

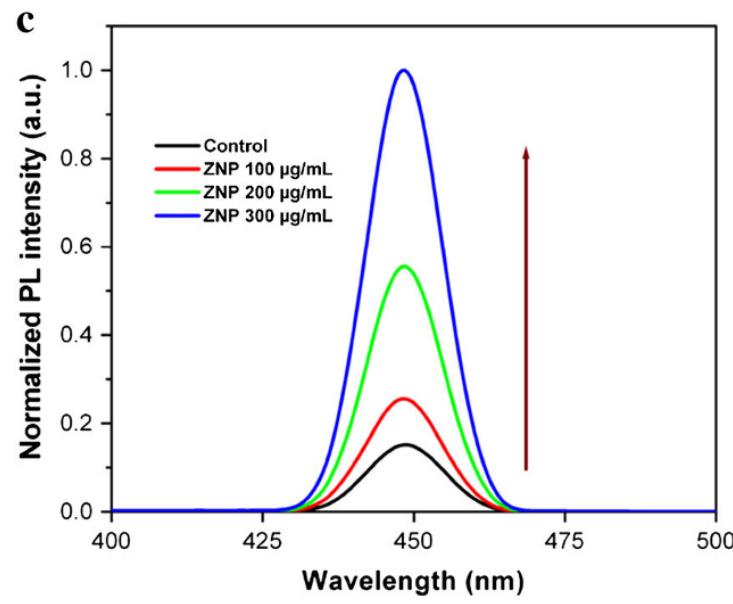

Fig. 3 a Cell membrane integrity study of $E$. coli cell (MTCC 443); b LPS release study by SDS-PAGE, panel $i$ control, panel ii ZNPtreated $E$. coli (MTCC 443); c outer membrane permeability study of

Inner membrane permeabilization assay

When the inner membrane (IM) became compromised, $\beta$ galactosidase, a normal endoenzyme could permeate the cytoplasmic membrane. The ability of ZNP to permeate $E$. coli IM was evaluated by the production of cytoplasmic $\beta$-galactosidase within bacteria grown in lactose containing media. When $E$. coli suspensions were treated with ZNP, there was immediate release of $\beta$-galactosidase which attained maxima after about $60 \mathrm{~min}$ (Fig. 3d). For control suspensions, there was a lag of about $30 \mathrm{~min}$ before $\beta$ galactosidase release and was released slowly. The enhanced release of cytoplasmic $\beta$-galactosidase caused by ZNP indicated that the permeability of IM was increased. This result was in good agreement with the other findings for $E$. coli cells.

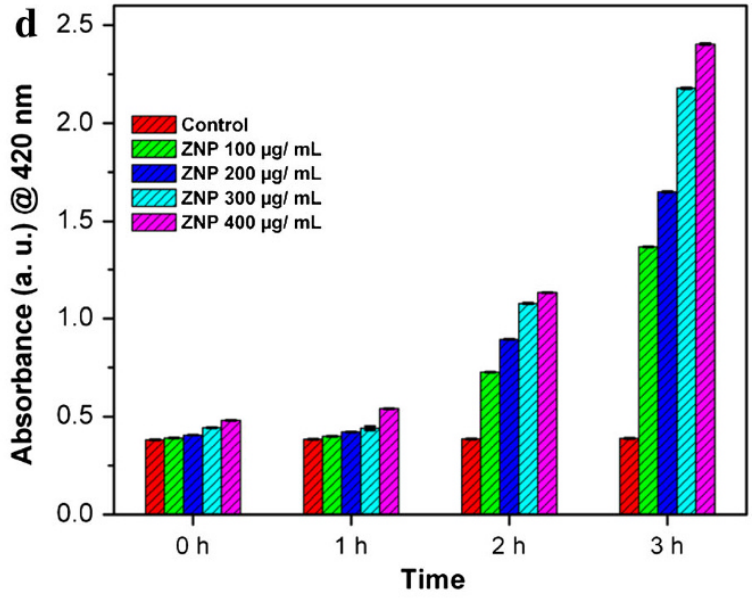

E. coli (MTCC 443); and d inner membrane permeability study of E. coli (MTCC 443)

Cell morphology study by FESEM and TEM

Healthy, uniform, regular, uninterrupted cell surface of control cell of bacteria (Fig. 4a) under FESEM while ZNPtreated E. coli $(200 \mu \mathrm{g} / \mathrm{mL})$ expressed cell deformation and discontinuity of cell wall (Fig. 4b). The treated samples had shriveled and inchoate morphologies. The same observation was also evident from TEM analysis. Control bacterial samples showed uniformity without distribution of ZNP on to it (Fig. 4c); meanwhile treated bacterial samples were ruptured while distinct internalization of samples within the cellular system was noted (Fig. 4d). EDX spectra of ZNP-treated bacterial sample confirmed the presence of $\mathrm{Zn}$ within the sample. About $16 \%$ of $\mathrm{Zn}$ was present within the treated sample. This result justified that ZNPs were readily internalized within the sample cell 
Fig. 4 Surface morphology of: a control and b ZNP-treated E. coli (MTCC 443) by FESEM; c control and d ZNP-treated E. coli (MTCC 443) by TEM
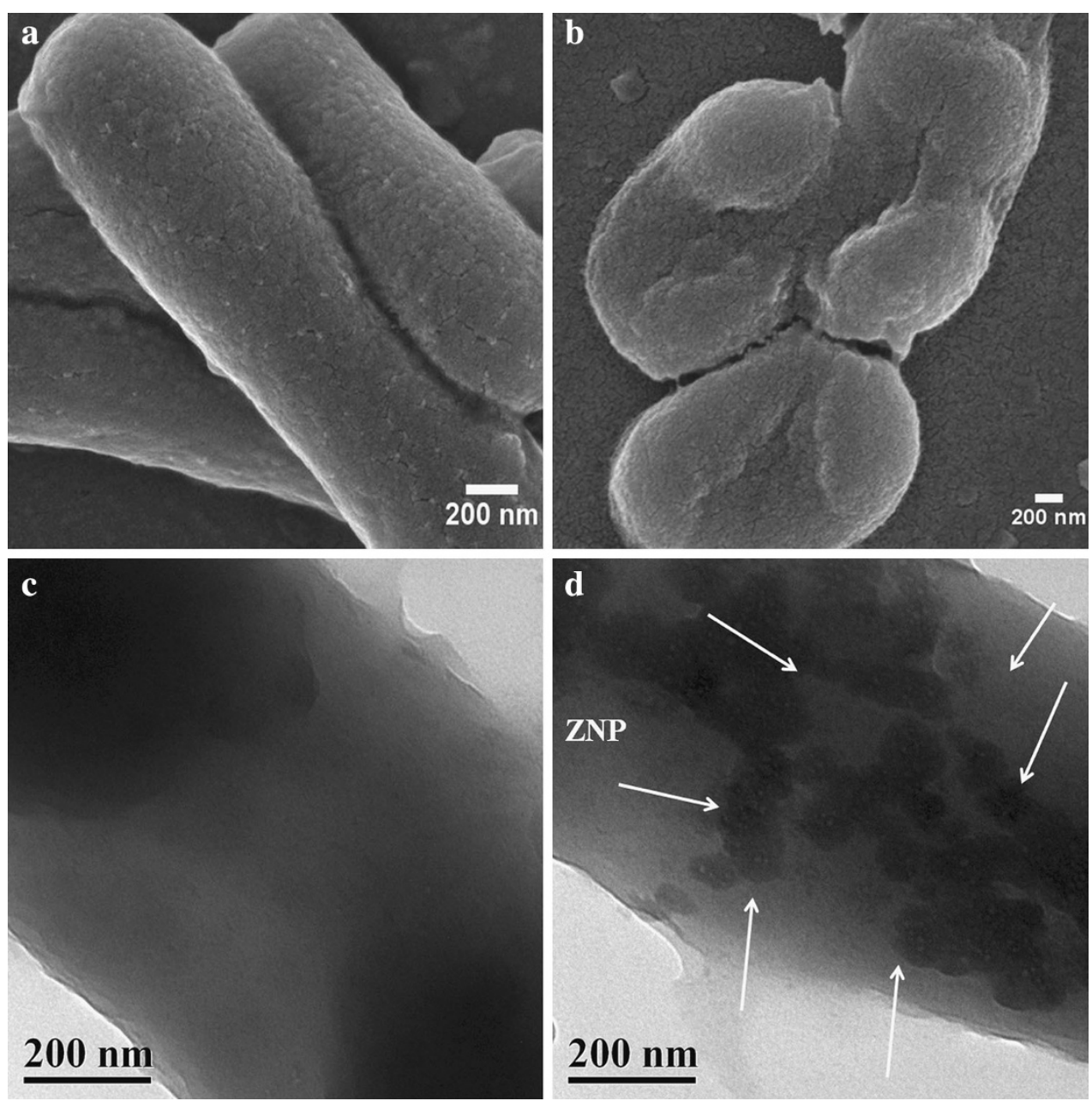

and corroborated with other experimental findings where internalization of ZNP within the sample cell was noted.

SDS-PAGE of whole cell proteins

Comparison of the whole cell proteins of control E. coli with ZNP-treated E. coli by SDS-PAGE analysis (Fig. 5a) showed that the protein profile of the control cells was different than that of ZNP-treated cells. Differences were observed in the expressed proteins but the identity of the proteins was not investigated further in this study. The changes in the protein expression profile were probably due to the damage of proteins in treated cells by ZNP compared to control.

Cell permeabilization study by confocal microscope and bioavailability

When bacterial sample was treated with RITC-conjugated ZNP, a clear distinct distribution of RITC-conjugated ZNP was observed on the bacterial sample. Treated samples exhibited bright red color at $540 \mathrm{~nm}$ excitation wavelength under confocal microscope (Fig. 5e-g), while control sample did not exhibit any bright red fluorescence at all (Fig. 5b-d). Therefore, confocal microscopic analysis also revealed the bioavailability of ZNP on the bacterial sample. Bioavailability of ZNP to E. coli was further supported EDX analysis associated with SEM. About $11.51 \mathrm{wt} \%$ of $\mathrm{Zn}$ content was found to be present on the treated bacterial cell (Fig. S1).

Carbonyl content as a marker of oxidative stress

Here, carbonyl formation as an indicator of oxidative stress was studied by DNPH binding assay. ROS could lead to side chain oxidation of protein and hence oxidized product was indexed as a carbonyl marker (Krumova et al. 2009). Total protein was estimated using a standard procedure (Lowry et al. 1951). Post-treatment increase in protein damage was observed for ZNP at different concentrations (100 and $200 \mu \mathrm{g} / \mathrm{mL}$ ) after $24 \mathrm{~h}$ of inoculations in comparison with control samples (Fig. 6). Highest dose of ZNP $(200 \mu \mathrm{g} / \mathrm{mL})$ produced $32,001.5$ nanomol/mg of protein damage of $E$. coli cell with respect to control which produced only 21,050 nanomol/mg of protein damage. 

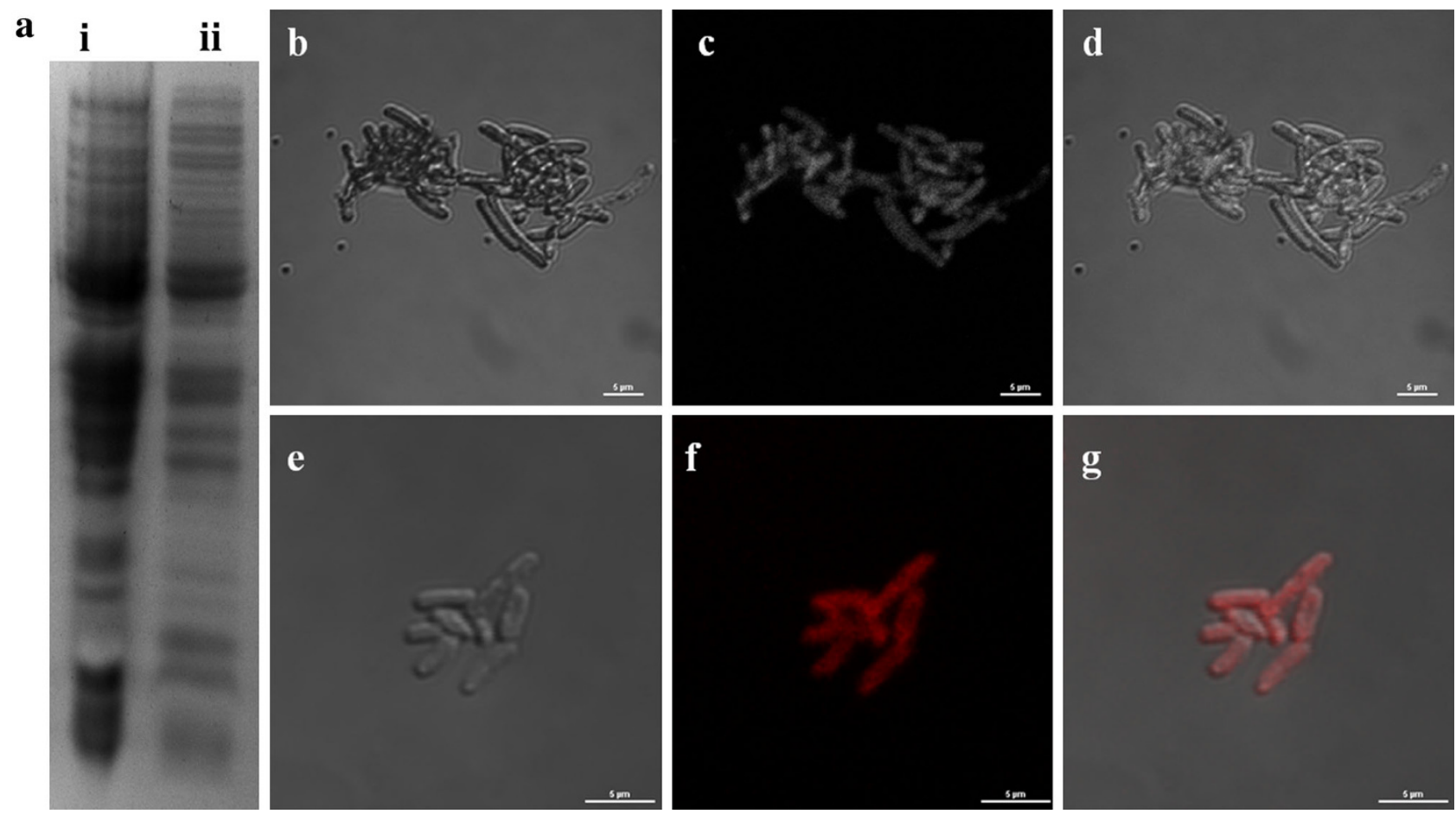

Fig. 5 a SDS-PAGE study of whole cell proteins of control (panel $i$ ) and ZNP-treated E. coli (MTCC 443) (panel ii); confocal microscopic image of (b-d) control E. coli (MTCC 443) sample; e-g RITC-tagged ZNP-treated E. coli (MTCC 443) sample, where the latter one clearly

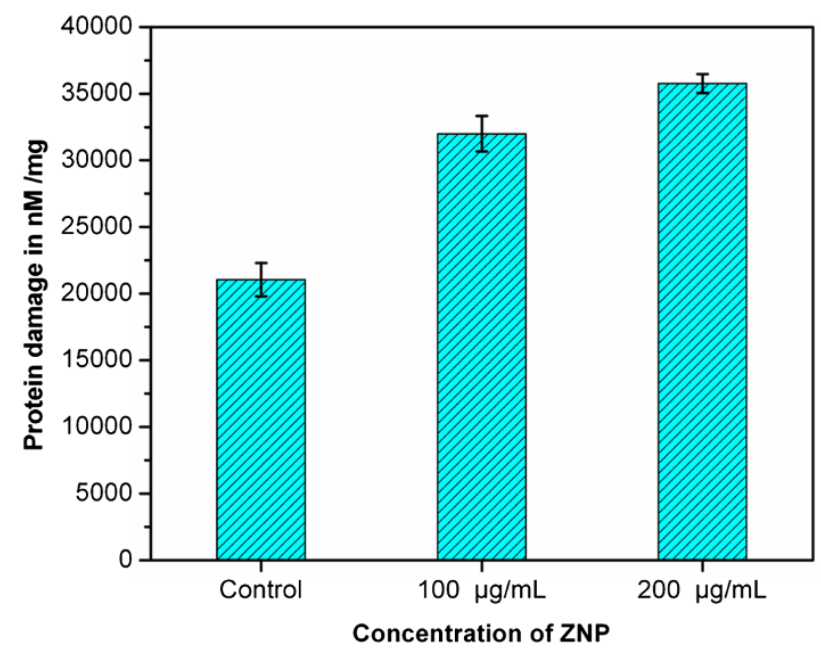

Fig. 6 Estimation of carbonyl content (as a marker of oxidative stress) of ZNP-treated E. coli (MTCC 443) compared to control

\section{Discussion}

In our study, we investigated probable mode of action study of newly synthesized ZNP as bactericidal agent. Electron micrographic study (HRTEM) confirmed that ZNP was in nanosized (around $20 \mathrm{~nm}$ ) and crystalline in nature. Morphology of this nanoparticle was also studied demonstrated bright red fluorescence at $540 \mathrm{~nm}$ excitation wavelength of RITC-tagged ZNP distributed on fungal sample

by FESEM. Although the particles went some sort of aggregation but the size was retained within nano-regime as evident from hydrodynamic radius measurement. This ZNP retained surface hydroxyl groups which confirmed its hydrophilic character. Therefore, it could easily interact with the hydrophilic OM counterpart of the bacterial cell. One of the utilities of this process was its easy synthesis within a short span of time with the aid of microwave oven. In addition, hexagonal crystal structure of ZNP was obtained without further annealing which added a dimension to this synthetic procedure in contrast to other synthesis processes (Bauermann et al. 2006). Low-cost precursors ease synthetic procedure, short span of time scale along with biocompatible reactants allowed this reaction to be called as 'green'. Importantly, hexagonal structure of ZNP with (101) plane, the highest intense one, confirmed the growth along [0001] direction which might have impact on bacterial system (Huang et al. 2008).

Several studies have suggested, two possible mechanisms could be involved in the interaction between nanoparticles and bacteria-(a) the production of increased levels of ROS, mostly hydroxyl radicals and singlet oxygen (Ostrovsky et al. 2009) and (b) deposition of the nanoparticles on the surface of bacteria or accumulation of nanoparticles either in the cytoplasm or in the periplasmic 


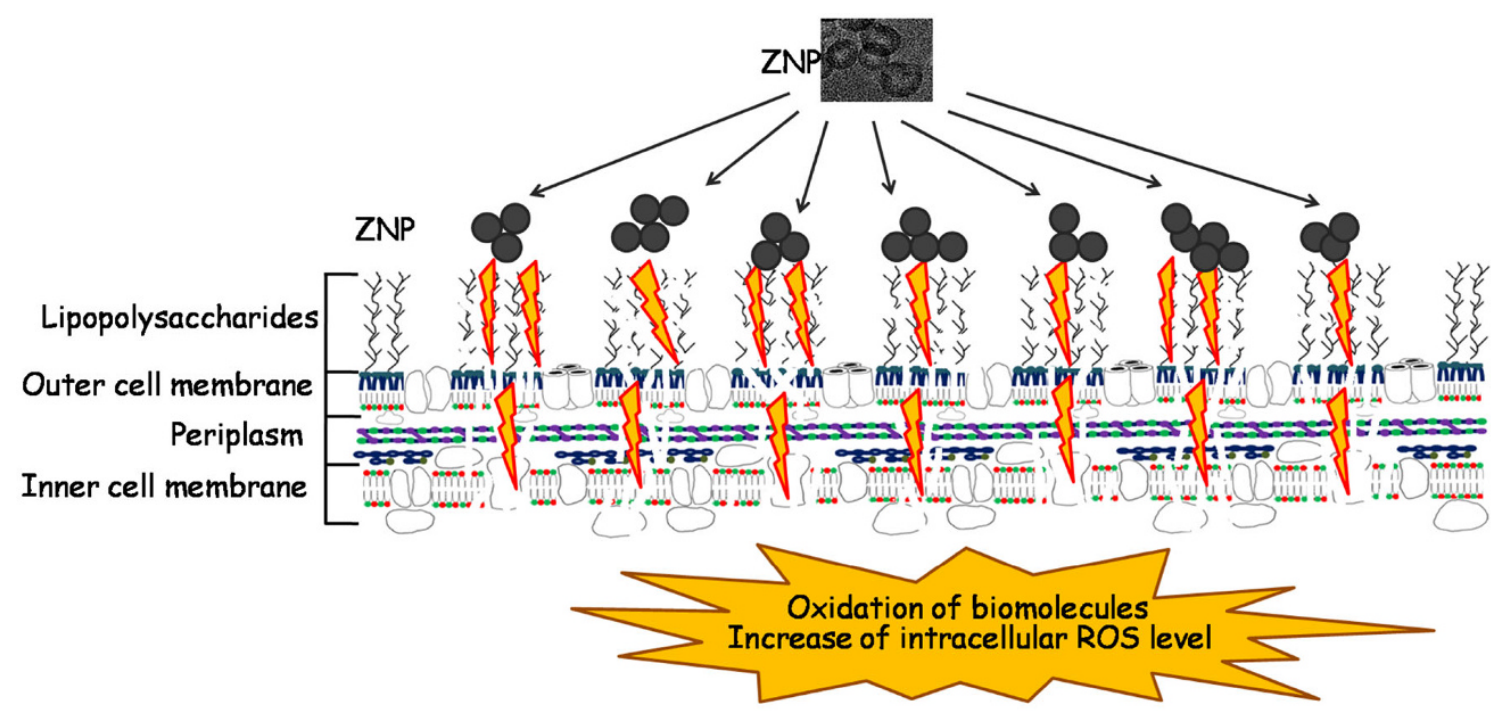

Fig. 7 Schematic representation of mode of action of ZNP against Gram-negative bacteria

region causing disruption of cellular function and/or disruption and disorganization of membranes.

From our experimental results, we speculated that ZNP is first bound with hydrophilic counterpart of LPS resulting in some sort of deformation within OM. LPS is known to give first line of defence to $E$. coli cell from foreign substances; ZNP damaged the LPS which is present at the outer side of OM of E. coli. A tandem destruction of IM was followed after disruption of the first line of defence of E. coli, i.e., LPS and OM. Finally, ZNP entered into cell cytoplasm and resulted cell death by ROS-mediated damage which was confirmed by spectrophotometric determination (Fig. 7). ROS-mediated damage resulted in enhancement of carbonyl content and ruptured the protein structure as evident from SDS-PAGE analysis. Bioavailability of ZNP within bacterial cell was confirmed by confocal microscopy and EDX analysis. This report will enlighten insights into the mode of action of ZNP and is expected to have a significant impact in near future for a detailed mode of action study.

Acknowledgments This work was generously supported by four major Grants from the Department of Biotechnology (DBT), GOI (Grant No: BT/PR9050/NNT/28/21/2007-2013, BT/PR8931/NNT/ 28/07/2007-2013, T/PR15217/NNT/28/506/2011-2014 and BT/ BIPP0439/11/10/2011-2014). We are grateful to the NAIP (ICAR) (Grant No. NAIP/Comp-4/C3004/2008-2014), the National Fund (ICAR) (Grant No. NFBSFARA/GB-2019/2011-2015) and ISI plan project funds (2008-2013) for providing financial support. We acknowledge Pathowind Clinical Laboratory, Kolkata for experiments related to clinically isolate samples. We acknowledge UGC, GOI sponsored central instrumental facility, CRNN, University of Calcutta. P.P is grateful to UGC, GOI for D.S. Kothari PDF. SM is thankful to CSIR, New Delhi for SRF.

Open Access This article is distributed under the terms of the Creative Commons Attribution License which permits any use, distribution, and reproduction in any medium, provided the original author(s) and the source are credited.

\section{References}

Anagnostakos K, Hitzler P, Pape D, Kohn D, Kelm J (2008) Persistence of bacterial growth on antibiotic-loaded beads: is it actually a problem. Acta Orthop 79:302-307

Applerot G, Lipovsky A, Dror R, Perkas N, Nitzan Y, Lubart R, Gedanken A (2009) Enhanced antibacterial activity of nanocrystalline $\mathrm{ZnO}$ due to increased ROS-mediated cell injury. Adv Funct Mater 19:842-852

Augustine R, Malik HN, Singhal DK, Mukherjee A, Malakar D, Kalarikkal N, Thomas S (2014a) Electrospun polycaprolactone/ $\mathrm{ZnO}$ nanocomposite membranes as biomaterials with antibacterial and cell adhesion properties. J Polym Res 21(3):1-17

Augustine R, Dominic EA, Reju I, Kaimal B, Kalarikkal N, Thomas S (2014b) Electrospun polycaprolactone membranes incorporated with $\mathrm{ZnO}$ nanoparticles as skin substitutes with enhanced fibroblast proliferation and wound healing. RSC Adv 47(4):24777-24785

Bauermann LP, Bill J, Aldinger F (2006) Bio-friendly synthesis of $\mathrm{ZnO}$ nanoparticles in aqueous solution at near-neutral $\mathrm{pH}$ and low temperature. J Phys Chem B 110:5182-5185

Chen CZ, Cooper SL (2002) Interactions between dendrimer biocides and bacterial membranes. Biomaterials 23:3359-3368

Clinical and Laboratory Standards Institute (2008) Performance standards for antimicrobial susceptibility testing: eighteenth informational supplement M100-S18. CLSI, Wayne

Dutta RK, Sharma PK, Bhargava R, Kumar N, Pandey AC (2010) Differential susceptibility of Escherichia coli cells toward transition metal-doped and matrix-embedded $\mathrm{ZnO}$ nanoparticles. J Phys Chem B 114:5594-5599

Hartmann M, Berditsch M, Hawecker J, Ardakani MF, Gerthsen D, Ulrich AS (2010) Damage of the bacterial cell envelope by antimicrobial peptides gramicidin S and PGLa as revealed by transmission and scanning electron microscopy. Antimicrob Agents Chemother 54(8):3132-3142

Helander IM, Latva-Kala K, Lounatmaa K (1998) Permeabilizing action of polyethyleneimine on Salmonella typhimurium 
involves disruption of the outer membrane and interactions with lipopolysaccharide. Microbiology 144:385-390

Huang Z, Zheng X, Yan D, Yin G, Liao X, Kang Y, Yao Y, Huang D, Hao B (2008) Toxicological effect of $\mathrm{ZnO}$ nanoparticles based on bacteria. Langmuir 24:4140-4144

Ibrahim HR, SugimotoY Aoki T (2000) Ovotransferrin antimicrobial peptide (OTAP-92) kills bacteria through a membrane damage mechanism. Biochim Biophys Acta 1523:196-205

Jones N, Ray B, Ranjit KT, Manna AC (2008) Antibacterial activity of $\mathrm{ZnO}$ nanoparticle suspensions on a broad spectrum of microorganisms. FEMS Microbiol Lett 279(1):71-76

Jung S, Oh E, Lee K, Yang Y, Park CG, Jeong S (2008) Sonochemical preparation of shape-selective $\mathrm{ZnO}$ nanostructures. Cryst Growth Des 8:265-269

Krumova EZ, Pashova SB, Dolashka-Angelova PA, Stefanova T, Angelova MB (2009) Biomarkers of oxidative stress in the fungal strain Humicola lutea under copper exposure. Process Biochem 44:288-295

Kumar KB, Raji P (2011) Synthesis and characterization of nano zinc oxide by sol gel spin coating. Recent Res Sci Technol 3(3):48-52

Lasserre JP, Beyne E, Pyndiah S, Lapaillerie D, Claverol S, Bonneu M (2006) A complexomic study of Escherichia coli using twodimensional blue native/SDS polyacrylamide gel electrophoresis. Electrophoresis 27:3306-3321

Liong M, Lu J, Kovochich M, Xia T, Ruehm SG, Nel AE (2008) Multifunctional inorganic nanoparticles for imaging, targeting, and drug delivery. ACS Nano 2:889-896

Lowry OH, Rosebrough NJ, Farr AL, Randall RJ (1951) Protein measurement with the folin phenol reagent. J Biol Chem 193:265-275
Maschhoff PM, Geilich BM, Webster TJ (2014) Greater fibroblast proliferation on an ultrasonicated $\mathrm{ZnO} / \mathrm{PVC}$ nanocomposite material. Int J Nanomed 9:257

Mitra S, Patra P, Chandra S, Pramanik P, Goswami A (2012) Efficacy of highly water-dispersed fabricated nano $\mathrm{ZnO}$ against clinically isolated bacterial strains. Appl Nanosci 2(3):231-238

Ostrovsky S, Kazimirsky G, Gedanken A, Brodie C (2009) Selective cytotoxic effect of $\mathrm{ZnO}$ nanoparticles on glioma cells. Nano Res 2:882-890

Patra P, Mitra S, Debnath N, Goswami A (2012) Biochemical, biophysical and microarray based antifungal evaluation of buffer mediated synthesized nano zinc oxide; in vivo and in vitro toxicity study. Langmuir 28:16966-16978

Raetz CRH, Whitfield C (2002) Lipopolysaccharides endotoxins. Annu Rev Biochem 71:635-700

Rodríguez-Tobías H, Morales G, Ledezma A, Romero J, Grande D (2014) Novel antibacterial electrospun mats based on poly (d, 1-lactide) nanofibers and zinc oxide nanoparticles. J Mater Sci 49(24):8373-8385

Sawai J (2003) Quantitative evaluation of antibacterial activities of metallic oxide powders $(\mathrm{ZnO}, \mathrm{MgO}$ and $\mathrm{CaO})$ by conductimetric assay. J Microbiol Methods 54:177-182

Szabo T, Nemeth J, Dekany I (2003) Zinc oxide nanoparticles incorporated in ultrathin layer silicate films and their photocatalytic properties. Coll Surf A 230:23-35

Zarrindokht EK, Pegah C (2011) Antibacterial activity of $\mathrm{ZnO}$ nanoparticle on gram-positive and gram-negative bacteria. Afr J Microbiol Res 5(12):1368-1373 